\title{
LO REAL Y LO FANTÁSTICO EN UN CUENTO DE ALFONSO REYES
}

Carmen V. Vidaurre Arenas

\section{(9) $\Theta \Theta$}

Esta obra está bajo una licencia Creative Commons

Reconocimiento-No Comercial-Sin Obra Derivada 



\title{
LO REAL Y LO FANTÁSTICO EN UN CUENTO DE ALFONSO REYES
}

\author{
REALISTIC AND FANTASTIC ELEMENTS IN A SHORT STORY BY \\ ALFONSO REYES
}

Carmen V. Vidaurre Arenas

\begin{abstract}
RESUMEN
En este trabajo estudiamos la forma en que la fantasía se manifiesta como resultado del empleo de ciertos recursos literarios, pero también como producto de la exploración en lo subjetivo y lo irreal, y como una modalidad de reactualización de un tópico que puede localizarse en la cultura clásica greco-latina, pero también en el arte modernista, presente en un cuento, escasamente estudiado, de Alfonso Reyes, publicado por primera vez en 1970, aunque escrito en 1915. Texto que corresponde a la definición que Tzvetan Todorov ofrece de lo fantástico, pero que también involucra aspectos que sobrepasan la definición formulada por el analista. El relato estudiado ofrece, además, la caracterización de un contexto real, desde una perspectiva que al ser contextualizada históricamente manifiesta una crítica respecto a los fenómenos y políticas de industrialización que afectaron al país en las últimas décadas del siglo XIX y las primeras del siglo XX.

Palabras clave: cuento fantástico, narrativa mexicana, análisis literario, crítica social implícita, tópico greco-latino.
\end{abstract}

\begin{abstract}
In this work, we going to study the fantasy and the way that this expression uses some literary resources, but in other way in the same time, it is a product of the exploration of the not real and subjective. It is a modality of reboot of a topic in the Greek-Roman culture, but also in the modernist art, present in a story, poorly studied, Alfonso Reyes, first published in 1970, though written in 1915. Text that corresponds to the definition Tzvetan Todorov offers of fantasy, but also involves aspects exceeding the definition given by the analyst. Additional characterization story was studied provides a real context, from a perspective that being contextualized historically manifests a critique of phenomena and industrialization politics that affected the country in the last decades of the nineteenth century and early twentieth century.

Key words: fantastic story, Mexican narrative, literary analysis, Social criticism implied, GreekRoman topic.
\end{abstract}

Nos proponemos analizar, en uno de los relatos de Alfonso Reyes contenido en Vida y ficción, la forma en que la fantasía se manifiesta como resultado del uso de ciertos recursos literarios, pero también como exploración en lo subjetivo, lo irreal, y como medio para renovar

Dra. Carmen V. Vidaurre Arenas. Universidad de Guadalajara. División de Artes y Humanidades del Centro Universitario de Arte, Arquitectura y Diseño. México.

Correo electrónico: vidaurrecarmenv@gmail.com

Recepción: 13- 07- 2015

Aceptación: 08- 12- 2015 
un tópico de larga tradición cultural. Fenómenos textuales que establecen una dialéctica con las referencias y la representación de un entorno real que es reinterpretado con propósitos creativo-expresivos, en dicho texto.

La obra narrativa de Reyes ha sido escasamente analizada, salvo algunos cuentos ("La cena" y en menor medida algunos otros, como "Silueta del indio Jesús"); pese a la importancia que el autor tiene, identificado como una de las grandes figuras intelectuales mexicanas, y al reconocimiento de que fueron objeto sus relatos por parte de destacados escritores -como Carlos Fuentes- que supieron ver en ellos "una carga de dinamita a largo plazo" (Garciadiego, 2014, p. 42). Sus relatos superan en número los que otros célebres autores mexicanos escribieron autores reconocidos tempranamente por él-, es el caso de Rulfo. El breve texto que analizamos cumple un siglo de haber sido escrito, y muestra la forma en que una ficción puede exponer veladamente elementos históricos y sociales que aluden a un trasfondo político, y que al ser tomado en cuenta, amplía la semántica de la narración. Además, "Floreal” no ha dado lugar a una lectura que vaya más allá de comentarios generales, al referirse de manera panorámica a la narrativa de su autor. Este escrito incluye elementos que dejan constancia de la importancia que lo nacional tiene en algunos relatos de Reyes, incluso en aquellos en los que no se desarrollan asuntos tocantes al indigenismo, la vida rural, la situación política del país vista desde los ojos de un extranjero, etc.; sino en los que hay una orientación a la fantasía. Sobre "Floreal", Alicia Reyes (2010, pp. 13-14) ha señalado: "aunque escrito en Madrid, febrero de 1915, es, totalmente, de ambiente mexicano del Norte. Se publicaría por vez primera en Vida y ficción (edición y prólogo de Ernesto Mejía Sánchez) [...] Narración que termina en cuadro, toques pictóricos que nos lanzan a una especie de misterio ecológico detonador de fantasía". José Luis Martínez (1989, pp. 7-20), en la introducción a las ficciones de Reyes, inexplicablemente no hace referencia a este relato que incluye en el volumen cuya esmerada edición estuvo a su cargo, como las obras completas de Reyes. Ernesto Sánchez Mejía destaca en su prólogo a la primera publicación de Vida y ficción que "la narración en tercera persona deja aflorar el "yo", y subraya también el final fantástico del relato contrastado con "el realismo del conjunto" (Sánchez-Mejía, 1970, p. 12). Concha Meléndez, al estudiar las ficciones de Reyes tampoco considera el cuento, por dar preferencia a narraciones de El plano oblicuo y Quince presencias (Meléndez, 1995, pp. 93-109). Sin embargo, "Floreal" ha sido calificado por Sergio Ortiz como una de las "pequeñas joyas literarias" de Reyes, en la que se recrean los tiempos de "expansión urbana y ferrocarrilera" (Ortiz, 2002, p. 60), y forma parte de las cuarenta y siete piezas que componen la antología narrativa de Alfonso Reyes, la cual fue: "dignamente preparada y prologada" (Castañón, 1997, p. 162). Lo que no justifica la poca atención que se le ha brindado a esta breve historia en la que: "más allá de la relación mimética entre realidad y ficción, lo contextual y lo textual, la vida y el arte, se pone de relieve la consideración de las circunstancias reales como estímulo de la actividad creadora" (Aatar, 2012, p. 20) y -añadimoscomo detonadoras de la ficción fantástica.

Antes de definir lo "fantástico" -siguiendo el ejemplo de Carmen Luna Sellés (2002, p. 12)-, deseamos recuperar las palabras de Rafael Gutiérrez Girardot respecto a los estudios teóricos de lo fantástico, pues sus palabras expresan la perspectiva y objetivos que hemos procurado aquí:

[...] lo fantástico es, como la literatura, un "ente fluido", para usar un concepto de Alfonso Reyes, o una "ambigüedad", como precisa Cleanth Brooks. Pero esto no implica renunciar a captar lo fantástico [...] En vez de buscar "a priori" en los textos determinadas características de lo fantástico, es necesario dar la palabra a los textos [...] preguntar por lo que en ellos se desvía y cómo y por qué se desvía de una determinada praxis [...] (Gutiérrez-Girardot, 1991, p. 29) 
"Floreal" es el segundo relato del volumen XXIII de las Obras Completas de Alfonso Reyes (1989, pp. 27-28). Se trata de un cuento de una página y dos párrafos, en el que un narrador personaje nos describe una anécdota singular, pues en un entorno de lo cotidiano se introduce un acontecimiento extraño que rompe con la lógica planteada y con aquello que se presentaría como natural o realista dentro del contexto narrativo que se nos ha descrito. Los protagonistas de esa anécdota son una recién casada y su esposo, quienes viven en una ciudad del Norte de México: Torreón (Coahuila), de lo que se ofrecen una serie de informaciones y pistas que así lo indican desde el principio; aunque este último dato sólo se señala de manera explícita casi al final del cuento.

El narrador inicia su historia en tercera persona y utilizando la modalidad retrospectiva, al referirnos la situación de los personajes y el escenario, pero su descripción no se limita al contexto espacio-temporal inmediato en que se ubican esos personajes de los que habla, ya que retrocede en el tiempo hasta el momento mismo de la fundación de la población en la que ellos residen, manifestando un grado de conocimiento sobre lo narrado que correspondería a un narrador omnisciente u omnipresente:

\footnotetext{
Estaba recién casada. Vivían en una ciudad del Norte llena del zumbido de las locomotoras. Se cruzaron varias línea de ferrocarril en medio de unos llanos polvosos, y en el cruce brotó una estación; cercano a la estación, un hotel; al lado dos o tres comercios, y junto a ellos las posadas de los traficantes, los paradores de los viajeros, las casas de juego. La ciudad era una estación grande, un campamento de comercio [...] (Reyes, 1989, p. 27)
}

El narrador ofrece detalles del espacio en el que reside esa recién casada, de quien no se ha hecho una descripción, dándole prioridad al origen del contexto social en que se ubica la historia, sin señalar información cronológica sobre el año, mes o día, en que ocurren los acontecimientos. Sin embargo, los datos que el narrador proporciona permiten identificar la ciudad en la que ocurre lo referido, pues Torreón tuvo un inicio vinculado al paso de los ferrocarriles, ciudad construida donde tenía lugar un cruce de vías (el Ferrocarril Central Mexicano y el Ferrocarril Internacional Mexicano, en 1888, y en la proximidad de una hacienda algodonera en la que había una edificación a manera de torre, de la que derivó el nombre de la hacienda principal y luego el de la ciudad), donde se construyó una estación de tren y posteriormente otras edificaciones a partir de la estación. Según Eduardo Guerra (1957, s. p.): "Andrés Eppen -considerado fundador de Torreón- con el auxilio del ingeniero Federico Wulff, demarcó el trazo de la ciudad y se había asegurado de adquirir los terrenos para la compañía de alemanes Rapp-Summer-Hermann (Contreras-Utrera, 1994, p. 65)”, de la que era administrador y socio.

Podremos observar que aunque los datos que el narrador proporciona son históricos, se relatan de manera que se introduce la fantasía, al no hacer mención de los sujetos responsables de las acciones contadas, por el uso de la forma impersonal del verbo y por utilizar un lenguaje metafórico que tiene como consecuencia que las vías y edificaciones figuren en los enunciados como sujetos actuantes por sí mismos: "Se cruzaron varias líneas de ferrocarril en medio de unos llanos polvosos, y en el cruce brotó una estación; cercano a la estación un hotel [...]" (Reyes, 1989, p. 27), y lo inanimado parece animado debido al uso del verbo "brotar", en preferencia de otras opciones de signos cuya semántica referiría a la acción de una manera realista (se construyó, se edificó; y no: "brotó una estación”). De modo que la fantasía se introduce aquí por el lenguaje empleado, un léxico que aunque no se aleja del lenguaje de uso cotidiano, es connotativo y está utilizado de modo metafórico, ya que implica una asimilación de las construcciones a una planta o líquido (que son algunos de los sustantivos a los que se 
aplicaría en su uso más socializado el término "brotó”). Esto último se vuelve más significativo cuando consideramos que la ciudad de Torreón ocuparía el lugar que mucho antes había sido una zona de lagunas, y hasta la primera mitad del siglo XIX una zona agrícola (la Hacienda de San Lorenzo de la Laguna, luego Rancho del Torreón), pero cuyo entorno ecológico y clima se modificaron parcialmente, ${ }^{1}$ cuando la construcción de la presa del Carrizal produjo el desvío del cauce de los ríos para beneficiar los cultivos de los hacendados, secando la mayoría de los cuerpos lacustres (a lo largo de la segunda mitad del siglo XIX).

Los edificios enumerados en la descripción dan cuenta de la vocación económica de la población descrita (servicios de hospedaje, comercio, tráfico, apuestas), al mismo tiempo que el escenario se caracteriza en el relato como: una ciudad llena de ruido, establecida en unos "llanos polvosos", espacio de tránsito de un lugar a otros, detalles también históricos.

El narrador continua haciendo referencia a acciones repetidas o acostumbradas que parecen descritas por un narrador testigo, al mismo tiempo que proporciona algunas informaciones que sólo podrían conocer los propios personajes que describe: "De cuando en cuando bajan del tren unos viejos [...] Entran en los garitos, echan un peso en la ruleta [...], vuelven al tren que ya silba, impacientes por seguir el viaje rumbo al Norte. Aquél peso que aventuraron, es el último peso que traían consigo" (Reyes, 1989, p. 27). Se pueden observar variaciones leves en la perspectiva del narrador, en unos casos manifestando las características propias de un testigo que observa a los viajeros (y sólo tiene conocimiento de lo "visible"), en otras expresando un grado de conocimiento propio de un narrador focalizado en los personajes y omnipresente, que conoce el estado de ánimo, el deseos, y la justa cantidad de dinero que llevan los apostadores (también podría tratarse de un narrador subjetivo que especula, pero nada hace poner en duda sus afirmaciones en el relato).

En esta primera parte del cuento, además de considerar los elementos del contexto urbano, el narrador le concede importancia a los fenómenos de migración social en varias ocasiones: I. "con mucha población de chinos $^{2}$ y yanquis" (Reyes, 1989, p. 27), II. "bajan del tren unos viejos pálidos, erguidos. Entran en los garitos, [...] vuelven al tren” (Reyes, 1989, p 27). El tema del tránsito figura incluso en la canción que se cita parcialmente en el cuento, cuando se describe a un ciego que canta en el andén de la estación: III. "Soy transitante de Torreón a Lerdo, /mis sufrimientos son por un amor" (Reyes 1989, p. 27). La letra original de la canción popular que es intertexto en su modalidad de cita con variante, identifica la población, pero señala una palabra distinta a "transitante", la variante está reforzando el campo semántico del desplazamiento (se trata de una variación en la letra -poco conocida- de la composición del Píoquinto González, músico popular duranguense, letra titulada: "De Torreón a Lerdo", la cual, según Manuel Terán Lira, autor del cancionero de Corridos Laguneros y cronista de la Comarca, tiene su origen en el año de 1898, y estuvo inspirada en el transporte que viajaba entre las dos ciudades. La letra original decía en su primeros versos: "Soy misionero de Torreón a Lerdo /mis sufrimientos son por un amor, /hora por hora corriendo el vapor, [...]" (Magallanes y Corpus, 2009, s. p.). ${ }^{3}$

Estas informaciones constituyen indicios de la forma en que la realidad social deja huellas en este relato, pero también del interés que se manifiesta en los movimientos sociales que afectaban la zona norte de México, en particular en una de las ciudades más jóvenes del país, al mismo tiempo que tales informaciones contribuían a darle verosimilitud al relato, sobre todo para un lector que conociera la región y su área urbana.

La referencia al tránsito, además, se va a relacionar en el texto con el cambio, no sólo por remitir al cambio de un lugar a otro, también porque figura en relación con otro 
tipo de "cambios" que se indican en la historia relatada (I. la residencia y estado civil de los personajes protagonistas, II. la fundación de una ciudad donde sólo había "llanos polvosos", III. la situación económica de los "viejos pálidos" que descienden del tren con un peso y ganan ciento, IV. el estado de los muebles de la recién casada que han envejecido rápidamente, V. el cambio de lugar de una mesa que pasa de la cocina al jardín, VI. el paso de la vida a la muerte de los "hombres", a que hace referencia el narrador -un tanto enigmáticamente- poco antes del desenlace del cuento, y VII. el cambio que se describe al final del relato, afectando a la protagonista y al mueble fabricado por su esposo).

Aunque el narrador no precisa cuál es la relación que sostiene con la recién casada o con el personaje masculino que la acompaña en su lugar de nueva residencia, relata que ella solía enviarle cartas breves y fotografías "del pueblo, de su casa, de su jardincillo, donde se la veía muy enflaquecida, junto a un mocetón [...]” (Reyes, 1989, p. 27). De este modo, el narrador queda ficcionalizado, por ser el personaje-destinatario de las cartas y fotografías enviadas por el personaje femenino, y por ello también queda identificado como un personaje que se encuentra lejos de la ciudad en la que reside esa recién casada del cuento (tácitamente se presenta al narrador como alguien que radica en otra población, por lo que para comunicarse con él, ella debe mandarle cartas). Este detalle también contribuye a la manifestación de la fantasía en el relato, pues el narrador es, al mismo tiempo: un personaje ausente, alejado del contexto en que ocurren los hechos, pero describe ese contexto como un testigo y como un narrador omnipresente, proporcionando informaciones que sólo en parte podría conocer a través de las cartas y fotografías recibidas, pues hay informaciones que derivan de una focalización en los personajes secundarios. Además, el narrador señala: "Me escribía cartas breves. Como no sabía escribir, sólo me decía las cosas esenciales" (Reyes, 1989, p. 27), comentario que parece indicar que el conocimiento del narrador sobre el contexto, no proviene de la recién casada que le escribe. Sin embargo, cuando el narrador refiere en específico lo que ella le contaba, utilizando una modalidad del discurso que Tzvetan Todorov (2004, p. 83) denomina discurso indirecto libre -pues en parte corresponde a enunciados contados y en parte a la reproducción literal de las enunciaciones del personaje, traspuestas en las palabras del narrador que las introduce e indica "quién habla"-, se puede observar que el personaje femenino ofrece algunos detalles:

\footnotetext{
[...] sólo me decía las cosas esenciales. Como el polvo de la región lagunera flota en el aire durante el verano -me explicaba-, los crepúsculos lucen aquí unos colores, unos tornasoles insospechados.

-Pero ¿qué sal tiene este polvillo que se come los muebles? Mi juego de sala se ha envejecido en unos meses. (Reyes, 1989, p. 27)
}

El personaje femenino queda caracterizado por sus enunciaciones, más que por una descripción, como alguien que tiene unos meses de vivir en la ciudad de Torreón. Si consideramos, además, que el personaje vive en una zona de clima extremoso, semidesértico, con vientos que producen tolvaneras y crean un ambiente muy polvoso, el personaje manifiesta una sensibilidad estética significativa, pues en lugar de hablar del calor, del adverso clima, de la sequedad del ambiente, describe los atardeceres, el polvo que flota en el aire durante el verano y envejece los muebles por la cantidad de sal que contiene (la laguna principal que existió en la zona era de agua salada), al mismo tiempo que ofrece informaciones derivadas de una "realidad" referenciada.

Sabremos también, por el narrador, que ella ha adelgazado notablemente y que recientemente se ha casado. 
El personaje masculino que es coprotagonista de la historia es descrito por el narrador, primero a partir de una fotografía, como: "un mocetón de buenos ojos que estaba en mangas de camisa, el puro en la boca y el rastrillo en la mano" (Reyes, 1989, p. 27). Se le caracteriza así como un hombre joven y su figura queda connotada por signos que refieren claramente a su masculinidad, de acuerdo con las convenciones de la época (el puro y el rastrillo), pero también por la actividad laboral física que se connota en la descripción (de "buenos ojos", comentario que puede aludir a la belleza o a la salud de los ojos, y "en mangas de camisa”). Más adelante este aspecto práctico y de laboriosidad manual se enfatiza al señalar: "Su marido tenía instintos de obrero" (Reyes, 1989, p. 27).

La anécdota principal de la historia, y que ha sido precedida por la descripción del contexto y la introducción de los personajes, iniciará hacia la parte final del breve relato, cuando el narrador refiera sobre el marido de la recién casada lo siguiente:

Un día quiso hacer una mesa para la cocina, tomó unas ramas y las clavó toscamente en una tabla. Era
primavera. (Como los hombres se nos mueren, este recuerdo me es amargo.) Los crepúsculos de Torreón
estaban como nunca gloriosos. El calor llenaba de ansias las cosas (Reyes, 1989, p. 28)

El párrafo citado no sólo nos informa sobre las modalidades específicas de la acción realizada por el personaje coprotagonista (se trata de una acción improvisada ante una necesidad derivada de un deseo), también nos informa de un hecho que queda en el sobreentendido y que deriva del comentario entre paréntesis que incluye el narrador -a modo de confesión al lector o de aparte teatral-, y que sugiere que el narrador refiere retrospectivamente la historia, ubicado en una época posterior a la muerte del coprotagonista de la misma, sugiriendo también que el narrador estaba vinculado afectivamente a ese personaje, por la especificidad del comentario "este recuerdo me es amargo" (aunque no se indica el tipo de relación que sostiene con el personaje, ni se informa claramente sobre la muerte de él, o de otros hombres).

La estrategia narrativa deja planteadas interrogantes que no resuelve y que conducen al lector a pensar en posibles respuestas al comentario que no tiene explicación, introducen la presencia del sobreentendido, de aquello que no se explica a profundidad, pero se deja "entrever".

Respecto a la anécdota, el grado de conocimiento manifiesto en las palabras del narrador sobre lo referido vuelve a ser, en la segunda parte del relato, el de un testigo que anuncia un desenlace, creando una atmosfera mediante el uso de un lenguaje poético: "el calor llenaba de ansias las cosas" (Reyes, 1989, p. 28), que humaniza las cosas. En esta parte se indica una estación del año que resultará significativa en el desenlace: la primavera, época de florecimiento y renovación de la naturaleza. Se señala también una hora del día -recurrente en el relato-, los atardeceres, referencia que permite establecer la relación entre el calor y la belleza de los crepúsculos. Pero, además, aquí, casi al final, se da a conocer explícitamente la ciudad que es escenario de la historia: "Los crepúsculos de Torreón” (Reyes, 1989, pp. 27-28).

Reyes pone notable atención en lo sensorial (I. "ciudad del Norte llena del zumbido de las locomotoras", II. "el polvo de la región lagunera flota en el aire durante el verano", III. "los crepúsculos lucen aquí uno colores, unos tornasoles insospechados"), e involucra asociaciones novedosas entre las palabras para producir figuras poéticas en las que lo inanimado se anima (I. "[...] y en el cruce brotó una estación", II. "el calor llenaba de ansias las cosas", III. "un ciego canta al roncar de un descoyuntado acordeón", IV. "polvillo que se come los muebles"). Fenómenos textuales que -como otros del escrito-, nos remiten por su especificidad y cronología a la estética modernista que estaba en pleno apogeo en la época. 
Aunque no hay ninguna información en el texto, sobre el traslado del narrador al lugar desde donde la recién casada le escribe, como tampoco hay indicaciones de que el narrador se encontrara presente en ese lugar cuando ocurren los hechos que son referidos al final cuento; el narrador ofrecerá datos en su descripción que sólo podría proporcionar un testigo muy próximo, pues observa en acercamiento los detalles que describe en los últimos párrafos del escrito:



El relato, pese a que ofrece informaciones verídicas sobre un contexto social real, deriva hacia una anécdota fantástica que involucra la verificación de acciones que no podrían tener lugar en esa realidad, ni corresponden a una lógica de lo verosímil planteada inicialmente en el cuento, porque una mesa construida rústicamente con ramas y una tabla, "echa brotes" en la cocina de una casa ubicada en una región de clima extremadamente seco, salino (semidesértico). Si ese hecho hubiera tenido lugar en un contexto selvático o de alta humedad, podría remitirnos a la presencia de "lo real maravilloso"; pero, desde una perspectiva "lógica", es imposible en el contexto geográfico en que nos ubica el relato.

Este acontecimiento, una mesa rústica que echa brotes, se presenta en la narración como un acontecimiento objetivo, y no derivado de la percepción subjetiva de alguno de los personajes o del narrador. Se trata de un acontecimiento maravilloso, de un hecho "desnaturalizado" y que se niega a ser el resultado de una perspectiva meramente subjetiva.

La referencia a los brotes pequeños que parecen surgir en la epidermis del personaje femenino, en la descripción ofrecida: "vista cerca, en su epidermis había también unos como brotecitos" (Reyes 1989, p. 28), deja en la ambigüedad si verdaderamente se trata de una germinación vegetal en la piel del personaje femenino; o si se trata sólo de una percepción subjetiva del narrador que emplea una comparación para identificar una cosa con otra que le es similar. Por lo que no podemos hablar, en este último detalle del cuento, de la presencia de lo maravilloso "puro", ni de una descripción que se niegue a una interpretación del hecho fantástico como producto de la mera visión subjetiva. ${ }^{4}$ En todo caso, tendríamos que señalar que este segundo detalle corresponde a lo que para Tzvetan Todorov caracteriza lo fantástico, cuando señala:

\footnotetext{
[...] lo fantástico se basa esencialmente en una vacilación del lector -de un lector que se identifica con el personaje principal- referida a la naturaleza de un acontecimiento extraño. Esta vacilación puede resolverse ya sea admitiendo que el acontecimiento pertenece a la realidad, ya sea decidiendo que éste es producto de la imaginación o el resultado de una ilusión... (Todorov, 1981, p. 114)
}

En el cuento, la fantasía narrada en la parte final deriva de dos fenómenos distintos: Primero, del contraste palpable entre el contexto descrito y lo referido como verificado de manera objetiva: los brotes vegetales en la mesa, hecho que puede considerarse como una exploración en lo irracional, lo ilógico, lo extraño, muy distinta de las exploraciones en lo irracional realizadas por los surrealistas, porque de manera previa el narrador ha ofrecido una serie de informaciones que marcarán el contraste entre el contexto geográfico y el hecho relatado, denunciando una planeación consciente; y no una incursión en el automatismo de los surrealistas. Planeación narrativa destinada a producir un efecto mediante el desarrollo de la anécdota inverosímil, extraña, fuera de lugar, y cuyo desenlace también involucra una semántica, en la medida en que se representa una naturaleza vegetal que desafía las leyes 
de la lógica y del clima, que germina, echando brotes, en un medio totalmente adverso. No poco significativo es tampoco que al inicio del relato el narrador haya expresado: "brotó una estación", haciendo presente un campo semántico en el que se connota lo vegetal y también lo líquido, para referirnos al origen de una ciudad, en una de las zonas más áridas del país (que pese a ello se denomina todavía "Región Lagunera"), adoptando un signo que forma parte de un campo semántico asociado a las características del entorno previas a la intervención de los hacendados y que justificaban la denominación que la región conserva. ${ }^{5}$

En segundo lugar, la fantasía deriva también de una comparación que sugiere una visión subjetiva y permite cierta ambigüedad; pero la verificación de la acción descrita, aunque fantástica, se ve reforzada por el contexto mismo en el que se describen los "brotecitos" en la epidermis de la recién casada, poco después de hacer referencia a los brotes en la mesa como hecho objetivo, lo que parecería favorecer la posibilidad de que lo señalado no fuera una mera visión subjetivo-comparativa del narrador.

Ahora bien, la "aparente metamorfosis" o cambio que se sugiere afecta al personaje femenino en el relato, y cuya verificación queda en la ambigüedad, hace presente la figura de un personaje humano que participa, por similitud o asimilación, de lo arbóreo, de lo vegetal: mujer-rama, mujer-tallo, mujer-vegetal, con pequeños brotes en la epidermis, ser híbrido. Esta figura es afín, aunque con sus particularidades concretas, a las de diversos personajes de la literatura y la tradición mitológica clásica greco-latina, personajes que teniendo figuras de mujeres se vieron transformadas en seres vegetales: como la dríade Dafne convertida en Laurel, Mirra o Esmirna transformada en Commiphora myrrha, Dríope transfigurada en "árbol de loto" (palmera o almez), Pitis convertida en abeto o pino negro, etc., así como es afín a otras figuras asociadas a lo arbóreo, como las Hamadríades, hijas de Hamadría, seres que participaban también, en cierta forma, de una naturaleza humano-vegetal, pues si se cortaba el árbol al que estaban ligadas, ellas morían. Estas asociaciones entre los femenino y la vegetación también pueden relacionarse con la personificación de la naturaleza a través de la figura de la "madre naturaleza".

Aunque el significado de ese "tópico" de la tradición mitológica greco-latina varía notablemente de un caso a otros, podemos identificar en el relato una "actualización” del mismo, actualización que tiene en el cuento su propio campo de significaciones y particularidades, en la medida en que la recuperación del tópico se une en el relato a la representación de un objeto hecho con ramas cortadas y clavadas que, sin embargo: echan brotes, y mediante el que se connota una naturaleza vegetal fértil y poderosa que subsiste vital después de su propia "muerte aparente", y a la que los recién casados llevan a "florecer en paz" en el jardín.

Es decir que, la fantasía también figura en el relato como una modalidad de la recuperación y actualización de un motivo mitológico de la tradición clásica greco-latina, pero unida a una representación específica de la naturaleza vegetal: persistente, renaciendo e invadiendo incluso la epidermis del personaje de la recién casada.

Nos parece importante señalar también que la representación de figuras femeninas asimiladas o identificadas con seres vegetales, no sólo fue motivo recurrente en la mitología y la literatura clásica, tan apreciada por Alfonso Reyes, fue asimismo un motivo frecuente en el arte modernista, contemporáneo a la época de escritura del cuento, movimiento en el que desde la última década del siglo XIX estaba representado en México por numerosos autores (Manuel Gutiérrez Nájera, Salvador Díaz Mirón, Enrique González Martínez, José Juan Tablada, Rubén M. Campos, Amado Nervo, Manuel José Othón, Rafael Reyes Spíndola, Luis Gonzaga Urbina, 
Francisco González León, Francisco A. De Icaza, Rafael López, Efrén Rebolledo, Enrique Fernández Granados, María Enriqueta Camarillo, Ramón López Velarde, quien publicaría su primer libro de poemas un año después de la escritura del cuento de Reyes, etc.), a lo que habría que agregar el papel que desempeñó la Revista Azul, en la que se difundiría la obra de algunos de los más destacados representantes del modernismo hispanoamericano, y la Revista Moderna, sucesora de la anterior y uno de los principales órganos de difusión del modernismo, del que ha señalado Lily Litvak (1990, p. 47): "Recordemos que las plantas son, de hecho, la base del arte modernista". Litvak (1990, p. 23) ofrece abundantes ejemplos de la literatura y el arte, destacando que en el modernismo: "[...] una sensual invasión de lirios, orquídeas y rosas, se manifestó [...] asociada o fundida con una figura femenina, y formando un bosque de símbolos [...]". La valoración de la naturaleza se manifiesta también en la literatura modernista, en diversos elementos verbales, pero igualmente en abundantes alegorías, como las Estaciones del Año, la Madre Naturaleza, las personificaciones del paisaje, del fuego, del viento, en un léxico de lo vegetal, en figuras poéticas que involucran a la flora, etc. Esta recuperación de los elementos vegetales está con frecuencia ligada a un rechazo a la sociedad industrial que exalta lo mecánico, la industria. No en vano, al iniciar su estudio sobre la literatura modernista en Hispanoamérica, José Miguel Oviedo ha señalado un fenómeno se producían como resultado de la Revolución Industrial y la aplicación de la filosofía positivista: "las maravillas de la técnica no hacían sino mostrar [...] el desamparo espiritual del individuo" (Oviedo, 2001, p. 223). El mismo autor dirá un poco después:

\footnotetext{
[...] se produce [...] un movimiento estético [...] que reacciona contra el arte imitativo y la utopía maquinista, y plantea una vuelta a las formas naturales, fluidas [...] crea una simetría entre los motivos florales y las formas femeninas: los trajes parecen flores, los capullos parecen senos [...] Este movimiento se llamó Art Nouveau [...] y se originó casi simultáneamente en Francia, e Inglaterra, donde también se llamó Modern Style [...] adoptó diversos nombres en el resto de los países europeos [...] El Art Nouveau es la analogía o metáfora plástica que mejor puede caracterizar a nuestro modernismo (Oviedo, 2001, p. 223)
}

Por otra parte, son muchos ya los autores que han destacado la importancia que en el modernismo tuvo el relato fantástico, entre ellos Carmen Luna, quien destaca la presencia de "lo extraordinario, lo mágico, lo misterioso, lo irracional formando parte de la realidad" (LunaSellés, 2002, p. 19) en la narrativa modernista y analiza algunas de sus variadas modalidades. Valioso estudio al que se suman muchos otros investigadores (Ana Casas, Dolores Phillipps López, Ramón Luis Acevedo Marrero, Dolores López Marín, Oscar Hahn, Raquel Areas Careaga, Eva Varcárcel, Mario Gallardo y un muy prolongado etcétera), que han abordado la presencia de lo fantástico en la narración breve modernista.

Pero, la presencia de lo fantástico no excluyó diversas modalidades de crítica con un enfoque ideológico específico, y al ofrecer un panorama de estudios realizados sobre el modernismo, Javier Blasco destaca el trabajo de Giovanni Allegra, respecto al cual señala: "Giovanni Allegra [...], partiendo de la ya consolidada definición del Modernismo como "crisis general del espíritu' (generadora de una reacción espiritualista contra el positivismo científico, el industrialismo y el mercantilismo burgués), reivindica para el movimiento un 'fondo ideológico’ del que la crítica, por lo general, se ha olvidado" (Blasco, 1987, p. 37).

Ahora bien, si el motivo de lo vegetal fusionado a la figura femenina constituyó uno de los diversos elementos que manifestaba un rechazo hacia la sociedad industrial, en diversos autores y artistas modernistas que exaltaban la naturaleza cargándola de sensualismo, humanizándola, no podemos ignorar que en el cuento de Alfonso Reyes también figura la referencia destacada a un motivo que fue símbolo de la industrialización, el ferrocarril: 
Con la entrada en funcionamiento del ferrocarril, las principales ciudades se fueron interconectando. [...con] la infraestructura que promovieron inicialmente las empresas [...] Así mismo, estos avances mecánicos, produjeron grandes cambios socio-económicos [...] una reacomodación poblacional en base al desarrollo industrial que estaba ligado estrechamente al ferrocarril... (Herrería, 2010, p. 2)

De manera que el ferrocarril no únicamente constituye un signo que refiere al desarrollo industrial, también a la migración y a los cambios sociales de finales del siglo XIX y principios del XX.

En el cuento de Alfonso Reyes, la ciudad "brota" en el cruce de unas vías de tren justamente, tal y como ocurrió con la ciudad de Torreón que es caracterizada como un lugar de migrantes, comerciantes y viajeros (que apuestan el único peso que llevan consigo, impacientes por partir), una ciudad cuyo desarrollo gira en torno al ferrocarril, polvosa, con un polvillo salino que envejece los muebles, hecho que plantea un marcado contraste entre ese entorno y la anécdota final en la que de una mesa rústica salen "brotes", y que es fabricada por un personaje que tiene "instinto de obrero". Podemos percibir una oposición entre contenidos semánticos que se relacionan con: lo industrial, el tránsito, el polvo, lo envejecido; y otros que refieren a la renovación vegetal, la naturaleza, lo no mecanizado, el trabajo manual.

Aunque el ferrocarril constituye todavía un símbolo de la industrialización, se va a asociar en la época de producción del cuento a otros fenómenos derivados de su uso, que fueron objeto de rechazo entre los artistas de la época, según observa Antonio Herrería, al considerar una obra de Lily Litvak, en la que se analiza el anti-industrialismo en la literatura en español, pues Herrería destaca sobre la transformación social debida a la industrialización lo siguiente:

[...] las consecuencias de esta transformación, son en parte, la causa por la cual se desarrolla entre los intelectuales un sentimiento de rechazo.

Entre estas consecuencias, se encuentran la aparición de nuevas clases sociales emergentes, como son la burguesía y el proletariado. La clase proletaria se nutría principalmente de la migración [...] que se hacinaba [...] con el añadido de precariedad laboral, por el exceso de mano de obra no calificada [...] (Herrería, 2010, pp. 2-3)

Podremos notar que en el cuento, la presencia del ferrocarril está asociada justamente a la migración.

En el escrito también se hace referencia, aunque indirectamente, al proletariado (el esposo tenía "instintos de obrero"), y a una actividad manual no calificada realizada por el esposo, actividad de la que deriva la mesa rústica mediante la que se introduce lo fantástico en un relato, en el que en principio se ofrecen datos que permite identificar la ciudad que es escenario del cuento.

Al mismo tiempo, a lo largo del relato se percibe una tensión entre la narración objetiva de un narrador testigo que describe "lo que ve", y la narración subjetiva focalizada en los personajes, que corresponde a la perspectiva de un narrador omnipresente (la mirada de Dios), narrador que además es ficcionalizado (narrador-personaje). Estos elementos permiten precisar que los opuestos se relacionan con aspectos ideológicos, que corresponden a una tensión producida en la época: "En Hispanoamérica [...] surge [...una] reacción literaria contra el positivismo y el arte burgués, dando entrada a la fantasía, el ensueño, el lirismo..." (LunaSellés, 2002, p. 26).

Alfonso García Morales (1992,pp. 69-146) se ha ocupado de precisar diversos aspectos sobre la instauración del positivismo en México y la postura crítica que frente a éste mantuvo el grupo del que formó parte Alfonso Reyes: el Ateneo de México. La investigación de García 
Morales destaca los diversos matices y contradicciones involucrados en el establecimiento del positivismo como filosofía institucional educativa, promovida desde el gobierno de Benito Juárez y mantenida posteriormente por Porfirio Díaz, como los matices ideológicos de las críticas dirigidas contra el positivismo durante el porfiriano, y ha descrito el contexto político en que esas críticas se producían, por lo que no vamos a detenernos en estos puntos. Sólo deseamos destacar que en el cuento se hacen visibles una serie de signos que expresan contenidos ideológicos afines a esas confrontaciones que tanto el Ateneo de México, como muchos otros escritores y artista modernistas hispanoamericanos sostuvieron frente a diversos postulados positivistas.

En el cuento, entre los signos que portan elementos ideológicos de oposición al positivismo se encuentran: I. la incorporación del enfoque subjetivo y el omnipresente del narrador, II. la anécdota fantástica que implica una representación particular de la naturaleza vegetal, III. La asociación entre esa naturaleza vegetal y las figuras de un personaje que tiene "instintos de obrero", IV. La identificación de la naturaleza y de un personaje femenino, mediante la reactualización de un tópico mitológico greco-latino que también figuró en el arte modernista, V. la representación de una ciudad industrial como espacio de tránsito y comercio, de apuestas, de traficantes, como ciudad en la que los muebles envejecen rápidamente, en la que flota el polvo, y cuya principal o única belleza son los atardeceres "gloriosos". Consideramos estos elementos como portadores de una postura ideológica opuesta al positivismo, porque sabemos que en éste se considera que la base de la información y del conocimiento sólo está en los fenómenos observables y objetivos, rechazando la subjetividad y todo aquello que pudiera estar asociado a la metafísica, a lo religioso, y a esa visión omnipresente capaz de conocer los deseos y pensamientos de otros. El positivismo, además, sostiene que esos fenómenos observables son los únicos que permiten el desarrollo de la ciencia y la tecnología, al mismo tiempo que defiende la lógica, el enfoque realista, y ve a la naturaleza como algo que debe controlarse, dominarse, en tanto proporciona materias primas, recursos naturales que deben someterse a un proceso de explotación mecanizada, lo que involucra una concepción desvalorativa de la naturaleza. ${ }^{6}$ Recordemos que en el positivismo la industrialización es altamente valorada, porque desde el punto de vista de esta concepción filosófica, la mecanización permitía el progreso, la riqueza derivada de ese control y dominio sobre la naturaleza. ${ }^{7}$ No podemos olvidar que el positivismo fue la base filosófica de la sociedad burguesa industrial, en la que el proletariado y otros grupos sociales pasaron a ocupar lugares de marginalidad, ${ }^{8}$ entre ellos los artistas, ${ }^{9}$ de aquí también su reacción. Además, para los positivistas: "Cobijados bajo la visión mecanicista del mundo donde toda la naturaleza era inanimada [...] La naturaleza transitaba a los ojos del hombre, de ser una madre tierra, femenina y compañera; a objeto de estudio, experimentación y explotación, y los seres vivos que la poblaban [eran] cosas de investigación" (Ojeda, 2008, p. 6).

En el cuento también se involucran signos que permiten identificar una crítica implícita a las consecuencias de las políticas económicas y de desarrollo implementadas durante el porfiriato, pues no podemos ignorar que la fundación y el auge específico que tuvo la ciudad de Torreón durante los primeros años del siglo XX, fueron resultado de esas políticas, que irónicamente fueron las mismas que asumirían quienes sucedieron a Díaz, Madero (hijo de quien fue gobernador porfirista de Coahuila) y Carranza (Gilly, 1994, p. 339). Esta crítica implícita a las políticas económicas del Porfiriato deriva del hecho de que el narrador ha elegido como escenario de su relato, una ciudad que fue de las más favorecidas por Porfirio Díaz, ciudad que Reyes caracteriza de una manera específica, y no como espacio de riqueza 
y beneficio colectivo, ya que Torreón no es presentada como una ciudad exitosa comercial e industrialmente, con hoteles de lujo, empresarios europeos y norteamericanos. Los signos que se incluyen en el cuento presentan a esa ciudad como espacio de migrantes, apostadores, traficantes, gentes sin arraigo, de paso, gringos viejos que vienen a enriquecerse con un peso, hombres impacientes por irse, ciudad contaminada por un polvillo salino. Torreón se presenta como un espacio que se contrapone a la anécdota fantástica en la que lo vegetal invade las ramas cortadas y la epidermis del personaje femenino. Es así que un contexto de ferrocarriles y hombres en tránsito, se contrasta con la pareja de recién casados, con la actividad la actividad laboral improvisada, manual, y realizada por un simple deseo del esposo, con el jardincillo de la casa de recién casados. Lo cual se vuelve muy significativo si consideramos que en la época inmediata anterior a la escritura del cuento, la ciudad de Torreón: "[...] ubicada en un nudo ferrocarrilero y convertida en centro importante [...], tuvo el mayor crecimiento de las últimas décadas del porfiriato" (Contreras-Cruz, 1994, p. 169). Esta última afirmación se comprueba también al estudiar la historia del ferrocarril en México, pues observamos que en la política de Díaz, el impulso al ferrocarril fue destacado y respondía a intereses de las compañías norteamericanas, en tanto permitía el transporte de materias primas que requería el país vecino: En 1880 se otorgan tres importantes concesiones ferroviarias a inversionistas norteamericanos, con toda
clase de facilidades para la construcción e importación de material y equipo rodante, que dieron origen al
Ferrocarril Central, al Ferrocarril Nacional y al Ferrocarril Internacional. Al concluir el primer período
de gobierno del General Díaz, en 1880, la red de vías férreas de jurisdicción federal contaba con 1,073.5
Km. (Domínguez-Valencia, 2009, p. 21)

Los estudiosos del tema reconocen que durante el gobierno de Díaz ciertas ciudades se verían beneficiadas por encima de otras, con las innovaciones tecnológicas impulsadas para el "progreso":

\footnotetext{
El desarrollo de una producción industrial y su concentración en ciertas poblaciones apareció como un fenómeno [...] estrechamente relacionado con el advenimiento del ferrocarril. Torreón y Gómez Palacio, de escasa importancia industrial [...] se convirtieron desde la década de 1890 en las principales embarcadoras de jabón, aceites y otras manufacturas que abastecieron mercados remotos [...] (KuntzFicker, 1999, p. 18)
}

A finales del Porfiriato, Torreón era el más importante nudo ferroviario del país, donde se habían establecido industrias, como la Metalúrgica de Torreón, la Jabonera de la Laguna, la de Dinamita y Explosivos, fábricas de hilados, ladrilleras, sucursales bancarias, comercios y hoteles de lujo (González-Morales, 1997, pp. 61-62). Había negocios de contrabando y apuestas, que incrementaban el capital circulante. La población quedaba relativamente próxima a una zona minera de interés para los estadounidenses, con la que la estación de tren conectaba (Contreras-Delgado, 2002, pp. 61-62).

La selección del contexto del cuento que ha hecho Alfonso Reyes se vuelve más significativa si consideramos que durante los 9 años que median entre la derrota de Díaz y el gobierno de Carranza, el gobierno del país había estado en manos de un conjunto de personajes que en su mayoría eran de Coahuila, exceptuando el año del gobierno de Huerta, los 45 minutos del gobierno de Pedro Lascuráin y el mes de gobierno de Carvajal. Como gobernador de Coahuila, Carranza representó los intereses identificados con empresarios y hacendados locales, y a ello obedecieron gran parte de sus acciones y los conflictos generados con otros líderes revolucionarios. Esos intereses fueron los que determinaron que ya en la presidencia fuera objeto de resistencias (Gilly, 1994, p. 339). Además, el proceso de expansión 
del capitalismo, en su modalidad imperialista, al que François Perus se refirió al estudiar el modernismo, hacía particularmente importantes las ciudades del norte de México en la época, ya que eran proveedoras de materias primas y mano de obra económica para Estados Unidos. También las hacía importantes porque en ellas se mostraban las consecuencias de ese expansionismo imperialista. Podrá observarse la importancia que el escenario del cuento adquiere entonces.

La situación en España, donde se encontraba Reyes al escribir el relato, no era menos mutable que la de la zona norte del país, pese a que España se mantuvo neutral durante la Primera Guerra Mundial. La propia experiencia vital de Reyes estaba también marcada por una serie de cambios y tránsitos. Había sido el hijo de un militar que fue gobernador de Nuevo León y miembro del gobierno de Díaz. En 1913, el padre de Reyes, luego de ser sacado de la prisión, había muerto en una emboscada, al inicio de la "Decena Trágica" que culminó con la muerte de Madero, contra quién Bernardo Reyes se había levantado en una acción que no parecía planeada por él, lo que, además de llevarlo a la muerte, lo hizo caer en el desprestigio; aunque en el momento en que el general Reyes se armaba contra Madero, éste ya se había ganado el descontento de numerosos sectores sociales:

El análisis del gobierno de Francisco I. Madero, de apenas 14 meses de duración, es digno de interés
porque logra ubicar con precisión el escenario nacional y los problemas que derivaron en una deficiente
administración gubernamental. Ello auspició un frente amplio de enemigos que llevaron al desenlace fatal
del Cuartelazo que estalló el 9 de febrero de 1913, atribuido por la historia oficial casi exclusivamente a la
acción del general Bernardo Reyes, y dejando de lado a otros actores que Canudas se detiene a analizar.
[...] En los alineamientos antimaderistas estuvieron también los hermanos Vázquez Gómez e incluso se
mencionó a Carranza como uno más de los conspiradores, al fin y al cabo todos ellos habían sido reyistas.
(Martínez-Assad, 2010, p. 157)

La mayoría de los investigadores coinciden en estos aspectos, incluso cuando atribuyen el descontento, no a una incapacidad de Madero sino a una serie de circunstancias de difícil solución (Gilly, 1994, pp. 117 y 119). Sabemos que la situación de "descontento" tenía antecedentes en el Porfiriato y que se manifestó también, por el rechazo de Bernardo Reyes a los "Científicos", aunque sin llegar a las armas, pero se trataba de diferencias significativas, al punto que se llegó a identificar a Bernardo Reyes como el mejor oponente de Díaz para la presidencia. Sin embargo, y a pesar de no saber las motivaciones del general Reyes (que estaba preso y fue sorpresivamente liberado), para levantarse contra Madero, es necesario observar que sus acciones coincidían con las de otros grupos sociales (Ramírez-Rancaño, 2008, p. 206).

Hemos señalado el papel que las vías férreas desempeñaron en el desarrollo económico, a éste tendríamos que añadir la enorme importancia que durante la Revolución Mexicana desempeñaron como blanco de los ataques revolucionarios y como recurso del que los rebeldes se apropiaron para hacer la Revolución. Patricio Juárez (2003, p. 27) hace un estudio en el que señala: "Madero asumirá el poder a principios de noviembre de 1911, y en los primeros días del siguiente año decide tomar medidas drásticas para frenar los ataques a los ferrocarriles". Es decir que, antes de resolver cualquiera de los apremiantes problemas del país, el recién electo presidente buscaría proteger los ferrocarriles y sus vías, que constituyeron la estrategia para "fomentar" el comercio exterior y que conectaban nuestro territorio con los Estados Unidos, permitiendo el abastecimiento de importantes materias primas (carbón, algodón, explosivos, etc.). Si a esto se suma que Díaz había otorgado concesiones petroleras a los europeos, y norteamericanos (Meyer, 1972, pp. 41-43), para favorecer a los contratistas de ferrocarriles, y a esto añadimos la Ley del 24 de diciembre de 1901 que autorizaba la explotación petrolera en baldíos, zonas federales, lechos corrientes y masas de agua, concediendo por diez años la libre 
importación de maquinaria, de productos y la exención de todo impuesto sobre la inversión, así como el derecho de compra de terrenos nacionales al precio de baldíos (Alemán-Valdés, 2007, pp. 20-23), comprenderemos mejor la importancia que el territorio norte cobraba en el desarrollo del capitalismo imperialista de la época, y los intereses que entraban en juego. No olvidemos que sobre el tema específico del petróleo durante el porfiriato, Meyer ha señalado:

\footnotetext{
La aparición de los primeros exploradores estadounidenses que vinieron en busca de petróleo se explica por varias razones, en primer lugar, porque la demanda del combustible era ya importante, sobre todo en los países industriales, en segundo término, porque México constituía la prolongación natural de los campos petroleros texanos [...] Durante el periodo en que el petróleo mexicano fue dominado por capital externo -es decir, de fines del siglo XIX hasta 1938- Estados Unidos produjo las dos terceras partes del petróleo extraído en el mundo. (Meyer, 2009, p. 31)
}

Así pues, pese a que el relato no trata de cuestiones políticas, el contexto social que caracteriza el escenario elegido en el cuento se vuelve muy significativo, máxime si consideramos que el contexto político afectaba directamente al autor, no sólo por ser hijo del general Reyes, también porque, estando ya Huerta en el poder (después de asesinar a Madero y a los potenciales oponentes a su gobierno, entre quienes destacaba el padre de Reyes), ${ }^{10}$ Huerta había invitado a Alfonso Reyes a ser su secretario particular, pero éste lo había rechazado, prefiriendo formar parte de la legación mexicana en París, hecho que ha sido interpretado como un exilio velado. Alfonso Reyes, recién casado y con un pequeño hijo, permanecería en París casi un año, hasta el inicio de la Primera Guerra Mundial, cuando Carranza suspendió la actividad de la legación mexicana, lo que dejó a Reyes y a los miembros de dicha legación sin trabajo. En 1914, Alfonso Reyes viajó con su familia a España, donde empezó su labor periodística, como medio para ganarse la vida. No volvería a México sino en la década de 1930, pero en el momento en que escribió el relato que nos ocupa, tenía un año de haberse instalado en Madrid, desde donde preguntaba y se respondía: “QQué será de México? -le dice a Pedro Henríquez Ureña en 1914-. Creo que todos están manchados y que es irremediable que sigan matándose" (Castañón, 1997, p. 35), lo que deja constancia que el escritor se mantenía informado sobre la realidad nacional y tenía una opinión precisa, pese a que las comunicaciones internacionales resultaban particularmente difíciles.

Si bien es cierto, como han observado los especialistas en sus obras y vida, que Alfonso Reyes evitó verse involucrado en cuestiones políticas, sobre todo después de la Revolución, este cuento nos descubre que las críticas al poder y a la realidad social nacional, no estuvieron ausentes de su ejercicio literario, pues se manifiestan veladamente incluso en este relato cuyas modalidades particulares atañen a diversas formas de introducir la fantasía y explorar en lo irracional, pues no excluye el contexto social y algunos de los fenómenos que lo afectaban. Así, pese a que el escritor ha evitado aludir explícitamente a aspectos políticos, parte de ese contexto soterrado en el relato, parece asomarse no sólo en la caracterización del escenario de su relato, también en el enigmático y no explicado comentario del narrador que figura entre paréntesis "(Como los hombres se nos mueren, este recuerdo me es amargo)".

Al hacer que lo insólito, se integre a la realidad cotidiana, Alfonso Reyes crea un cuento que se ajusta perfectamente a las convenciones que luego serían distintivas del relato fantástico moderno. Llama la atención que esta narración haya merecido tan poco interés por parte de los estudiosos de la obra de su autor, pues constituye un ejemplo notable del género, permitiendo simultáneamente una lectura mito-poética de un acontecimiento insólito presentado como algo cotidiano, como también permite una lectura que implica lo fantástico, 
irrumpiendo en la realidad, para expresar una postura crítica frente al resultado del desarrollo industrial y las políticas de "progreso" en el México de las primeras décadas del siglo XX.

\section{Notas}

1. No podemos ignorar que la zona forma parte del llamado Bolson de Mapimi, que se caracteriza por su clima desértico y extremoso.

2. Los chinos llegaron a México, principalmente, a partir de la firma del tratado con China, en 1888, durante el gobierno de Porfirio Díaz, algunos otros, lo hicieron a través de la migración ilegal. La gran mayoría de ellos venían a trabajar en el establecimiento de las vías férreas, constituían, junto con los indígenas, una de las pocas poblaciones que fueron objeto de racismo, pues la mayor parte de los extranjeros europeos y norteamericanos ocupaban niveles privilegiados en el país (Contreras-Utrera, 1994, pp. 57-78).

3. Información tomada de "Corridos de la Revolución y de la Laguna", corto audiovisual realizado en Torreón, por Aldo Magallanes e Iván Corpus Lozoya, a modo de "crestomatía", con base en la información proporcionada por diario El Siglo de Torreón, en un espacio multimedia (elsiglodetorreon.com), información difundida el 20 de noviembre de 2009, fecha en la que se entrevistó a Manuel Terán Lira.

4. Visión que manifiesta el deseo de romper con la perspectiva realista empirista, no para crear una fisura en la realidad, sino para incorporar lo subjetivo en ella. Sobre el tema se puede consultar el trabajo de Carmen Luna Sellés (Luna-Sellés, 2002).

5. La zona también llamada La Laguna o Comarca Lagunera debe su nombre a las trece lagunas superficiales y veneros que existían en el área, entre las que estaba la Laguna de Mayrán, que se alimentaba por ríos de temporal cuyos cursos fueron desviados por los terratenientes a partir del siglo XIX, en esa cuenca cerrada se estableció Torreón (1907), cuando la zona ya se caracterizaba por sus limitados recursos hídricos y por un clima más extremoso y seco que antes.

6. Como ha señalado Juan Eugenio Sánchez: “Cabe resaltar que la organización económica del espacio no depende necesariamente de sus recursos naturales (geo-físicos) sino de los intereses dominantes ya que, por un lado, no se utilizan necesariamente todos los existentes -especialmente los de los países dependientes subdesarrollados- y que, por otro, el proceso de transformación no se realiza, necesariamente, en el lugar de origen de las primeras materias, sino que se transforman en cualquier parte del mundo, allí donde los intereses económicos del poder consideren que les comportará una mayor apropiación global de excedente. En este sentido, la naturaleza solamente es una variable de segundo grado..." (Sánchez, 1979, p. 1/20).

7. "El verdadero objetivo de las ciencias no es buscar las causas ocultas de los fenómenos, sino sólo describirlos sistemáticamente, para poder hacer buenas predicciones. Las predicciones nos permiten actuar sobre la naturaleza; con ello se promueve el progreso tecnológico, la base de todo progreso humano." (Moulines, 1979, p. 1/20).

8. El tema ha sido ampliamente estudiado, pero vale la pena mencionar trabajos centrados en la época, que hacen aportaciones a lo ya estudiado, como: Gerardo González Ascencio, 2010, "Positivismo y organicismo en México a fines del siglo XIX. La construcción de una visión determinista sobre la conducta criminal de alcohólicos, mujeres e indígenas", en Alegatos 76, (México, Universidad Autónoma Metropolitana, septiembre-diciembre) 693-724; Alejandra Milhe para el caso de Brasil (2001, "Miradas cruzadas sobre la marginalidad social en el Brasil de entre siglos 1889-1914. Nina RodríguezJoao do Rio", en Orbis Tertius 8 IV, 69-83).

9. Rafael Gutiérrez Girardot ha hecho referencia a este fenómeno ampliamente en su libro Modernismo. Supuestos históricos y culturales. México: Fondo de Cultura Económica (Gutiérrez-Girardot, 1989, pp. 44 y ss.).

10. Así lo señala José Valerio Silva: "Parecía que la 'suerte’ protegía a Huerta, para que poco a poco se fuera quedando con la presidencia de la República de México. En efecto, primero se había encargado de la contrarrevolución contra Zapata y Orozco; después, Bernardo Reyes, su contrincante más fuerte, que quizá en una campaña cívica lo habría derrotado, murió ante el Palacio Nacional, dejándole franco el 
camino político. Esta suposición tiene sentido, pues Bernardo Reyes era un hombre con prestigio a pesar de haber cedido frente a Díaz; él fue la cabeza del antirreeleccionismo cuando don Porfirio lo toleró. A los partidarios de Reyes se debió la creación del ambiente propicio para que más tarde prosperara la acción de los hombres que, como Madero, hicieron la Revolución. También Reyes tenía simpatía, porque él fue el oponente más importante que tuvo José Ives Limantour, cabeza del grupo científico y quien igualmente aspiraba a la presidencia. Lo anterior, independientemente de que en el último momento estos dos prominentes hombres del porfirismo trabajaran juntos para conseguir el poder, cuando ya el ánimo de Díaz se había doblegado ante los triunfos de las armas revolucionarias" (Valerio-Silva, 1970, pp. 89-116)

\section{Bibliografía}

Aatar, A. (2012). Teorías y crítica literaria en la obra de Alfonso Reyes. Málaga: Publicaciones y Divulgación Científica de la Universidad de Málaga.

Alemán-Valdés, M. (2007). La verdad del petróleo en México. México: Biblioteca Mexicana de la Fundación Miguel Alemán.

Blasco, J. (1987). Modernismo y modernidad. Ínsula. Revista de Letras y Ciencias Humanas. $37,485-486$.

Castañón, A. (1997). Alfonso Reyes. Caballero de la voz errante. Monterrey: Universidad Autónoma de Nuevo León.

Contreras-Cruz, C. (1994). Urbanización y modernidad en el porfiriato. El caso de la ciudad de Puebla. Limpiar y obedecer. La basura, el agua y la muerte en La Puebla de los Ángeles (1650-1925). (167-188). Puebla: Claves Latinoamericanas-Centro de Estudios Mexicanos y Centroamericanos-El Colegio de Puebla.

Contreras-Delgado, C. (2002). Espacio y sociedad: reestructuración espacial de un antiguo enclave minero. México: El Colegio de la Frontera Norte-Plaza y Valdés.

Contreras-Utrera, J. (1994). Los comerciantes del puerto de Veracruz en la era del progreso. Anuario IX. 57-78. http://cdigital.uv.mx/handle/123456789/8543 [Consulta 03 de febrero de 2014].

Domínguez-Valencia, J. (2009). Desarrollo del transporte ferroviario en el mundo, siglo XIX y siglo XX. Caso de estudio México-Querétaro-Silao-Guadalajara. (Tesis para obtener el título de Ingeniero Civil). Instituto Politécnico Nacional de México. Escuela Superior de Ingeniería y Arquitectura.

García-Morales, A. (1992). El Ateneo de México (1906-1914). Orígenes de la cultura mexicana contemporánea. Sevilla: CSIC.

Garciadiego, J. (2014). Una amistad literaria. Monterrey: Tecnológico de Monterrey.

Gilly, A. (1994). La revolución interrumpida. México: Era.

González-Ascencio, G. (2010). Positivismo y organicismo en México a fines del siglo XIX. La construcción de una visión determinista sobre la conducta criminal de alcohólicos, mujeres e indígenas. Alegatos. 76, 693-724.

González-Morales, Á. (1997). El ferrocarril en la Comarca Lagunera. (Tesis de la Maestría en Historia). Universidad Autónoma Metropolitana. 
Guerra, E. (1957). Historia de la Laguna. Torreón, su origen y sus fundadores. Torreón: Casan.

Gutiérrez-Girardot, R. (1989). Modernismo. Supuestos históricos y culturales. México: Fondo de Cultura Económica.

Gutiérrez-Girardot, R. (1991). Literatura fantástica y modernidad en Hispanoamérica. Por E. Morillas-Ventura (Ed.). El relato fantástico en España e Hispanoamérica. (27-36). Madrid: Sociedad Estatal Quinto Centenario-Siruela.

Herrería, A. (2010). Lily Litvak y el fin de siglo. Magazine Modernista. 15. http:// magazinemodernista.com/2010/11/12/lily-litvak-y-la-generacion-del-98/ [Consulta 06 de febrero de 2014].

Juárez-Lucas, P. (2003). Los ferrocarriles y el maderismo 1910.1913. Mirada Ferroviaria. 16, 26-31. http://museoferrocarrilesmexicanos.gob.mx/secciones/cedif/boletines/ boletin_16/articles/mf16_04_tierra_ferroviaria_ferrocarriles_y_maderismo.pdf [Consulta 09 de marzo de 2014].

Kuntz-Ficker, S. (1999). Algunos efectos de la comunicación ferroviaria en el porfiriato. Por S. Kuntz-Ficker y P. Connoly (Coord.). Ferrocarriles y obras públicas. (105-138). México: CONACYT.

Litvak, L. (1990). España 1900. Modernismo, anarquismo y fin del siglo. Barcelona: Anthropos.

Luna-Sellés, C. (2002). La exploración de lo irracional en los escritores modernistas hispanoamericanos. Santiago de Compostela: Universidad de Santiago de Compostela.

Martínez-Assad, C. (2010). La primera guerra por el petróleo durante la Revolución Mexicana. Signos Históricos. 24, 154-158.

Martínez, J. L. (1989). Obras completas. (Vol. 23). México: Fondo de Cultura Económica.

Meléndez, C. (1995). Ficciones. Antología y cartas de sus amigos. (93-109). San Juan: Editorial Cordillera-Editorial Universidad de Puerto Rico.

Meyer, L. (1972). México y los Estados Unidos en el conflicto petrolero (1917-1942). México: El Colegio de México.

Meyer, L. (2009). Las raíces del nacionalismo petrolero en México. México: Océano.

Milhe, A. (2001). Miradas cruzadas sobre la marginalidad social en el Brasil de entre siglos 1889-1914. Nina Rodríguez-Joao do Rio. Orbis Tertius. 4 (8), 69-83.

Moulines, C. U. (1979). Génesis del Positivismo en su contexto científico. Cuadernos Críticos de Geografía Humana. 4 (23), 1/20. http://www.ub.edu/geocrit/geo23.htm [Consulta 18 de enero de 2014].

Ojeda-Sampson, A. (2008). El rompimiento de la humanidad con la naturaleza. Un abordaje desde la dialéctica crítica. Tecsistecatl. Revista Académica de Ciencias Sociales de México. 1 (4), 1/29. http://www.eumed.net/rev/tecsistecatl/n4/aos.htm [Consulta 12 de febrero de 2014].

Ortiz, S. (2002). Y López Velarde también se subió al tren. México: UNAM. 
Oviedo, J. M. (2001). Historia de la literatura hispanoamericana. (Vol. 2). Del Romanticismo al Modernismo. Madrid: Alianza.

Ramírez-Rancaño, M. (2008). La logística del ejército federal: 1881-1914. Estudios de Historia moderna y contemporánea de México. 36, 183-219.

Reyes, A. (1989). Obras completas, XXIII. México: Fondo de Cultura Económica.

Reyes, A. (2010). Prólogo. Cuentos. (7-20). México: Lumen.

Sánchez, J. E. (1979). Poder y espacio. Cuadernos Críticos de Geografía Humana. 4 (19), 1/20 http://www.ub.edu/geocrit/geo19.htm [Consulta 03 de marzo de 2014].

Sánchez-Mejía, E. (1970). Prólogo. Vida y ficción. (7-34). México: Fondo de Cultura Económica.

Terán-Lira, M. (s. f.). Cancionero. Corridos laguneros. Saltillo: Gobierno Municipal.

Todorov, T. (1981). Introducción a la literatura fantástica. México: Premia.

Todorov, T. (2004). Poética estructuralista. Madrid: Losada.

Valerio-Silva, J. (1970). Estudios de Historia Moderna y Contemporánea de México. (Vol. 3). México: Universidad Nacional Autónoma de México- Instituto de Investigaciones Históricas. http://www.historicas.unam.mx/moderna/ehmc/ehmc03/321.html [Consulta 19 de febrero de 2014]. 